\title{
Random Distribution of Cat/Dog Hair in Motor Vehicles
}

\author{
Larry Barksdale MA*1 and Jaclyn Humrich ${ }^{2}$ \\ ${ }^{1}$ Assistant Professor of Practice, College of Agricultural Sciences and Natural Resources, Forensic Science Degree Program, University of Nebraska- \\ Lincoln, USA
}

${ }^{2}$ Student College of Agricultural Sciences and Natural Resources, Forensic Science Degree Program, University of Nebraska-Lincoln, USA

Submission: October 26, 2017; Published: November 09, 2017

*Corresponding author: Larry Barksdale MA, Assistant Professor of Practice, College of Agricultural Sciences and Natural Resources, Forensic Science Degree Program, University of Nebraska-Lincoln, USA, Email: larry.barksdale@unl.edu

\begin{abstract}
The purpose of this research was to examine the frequency of dog and cat hair in motor vehicles in the Lincoln, Nebraska area. We looked specifically at cat and dog hair to see if there was a significant difference in the distribution between pet-owner vehicles and non-pet owner vehicles. Cat and dog hairs seemed to be the most common pet, the most likely to present in a vehicle, and the most often used to associate people, places, and things. Finding a significant distribution of cat and dog hairs in pet owner vehicles would support an association between cat or dog ownership, as an example, and cat or dog hair transfer to or from a crime scene. The results of the research indicated that cat and dog hair are ubiquitous in motor vehicles. More information than mere presence of a cat and dog hair in a motor vehicle would be needed to associate a person with a motor vehicle.
\end{abstract}

Keywords: Cat hair; Dog hair; Human hair; Distribution of hair; Pet owner; Non-Pet Owner; Association

\section{Introduction}

The research herein in is about hair. Hair is trace evidence. Contact between persons, places, and things leave a transfer of material from one to the other. Hair, perhaps, is the most prevalent transfer piece of evidence in modern society. It is commonly accepted among practitioners that it is no longer suitable for identification purposes, outside of DNA analysis. However, it continues to have value for investigative purposes in pointing towards possible associations between people, places, and things. It is rather intuitive that hairs can be transferred during physical contact. Such transfer can link a suspect to a victim, or a suspect/victim to a crime scene [1]. A scenario of this concept would be dog hairs in a motor vehicle in which the driver of the motor vehicle was assaulted by an unknown person, and the driver nor owner of the motor vehicle was a dog owner nor had history of contact with a dog.

The dog hairs might have provided information for a linkage between a suspect who owned a dog and the vehicle. An actual case scenario involved the apartment of a victim who was allergic to cats and dogs, and who would not allow anyone into her apartment who might transfer cat or dog hairs. Cat hairs were found in the apartment, and a suspect was developed that had a history of intimate contact with cats [2]. The cat hair information was used as supporting data in application for a search warrant. Houck provided an account of a casein 1985 in which a college student was kidnapped and murdered [3]. Hair examiner Harold Deadman used hair found in the trunk of a motor vehicle to strengthen the link between victim and suspect, and that linkage helped fill in pieces of the story that other evidence could not [3].

On the surface, it would have been a reasonable inference that the owner of a dog could be associated with the motor vehicle and the cat lover with the apartment of the assault victim. On the other hand, if cat and dog hair was ubiquitous in each environment the sufficiency of the hairs as associative evidence would be minimal at best. Hair evidence has come into question. The FBI announced that 2500 cases were under review in which hair matches were over stated by examiners [4]. The issue has become that outside of DNA analysis, hair at a crime scene cannot be used to identify a specific source. This, however, does not totally negate the potential value of hair evidence as data used for making investigative decisions on allocation of resources. The basis for this inference, however, requires more support from research to establish that hair evidence is not usually a part of a given environment. The null hypothesis for the research of this project was that there was no significance distribution of cat/dog hairs between pet owners and non-pet owners in motor vehicles in the Lincoln, Nebraska geographical area. 


\section{Materials and Methods}

\section{Literature Review}

Hair is composed of any outer morphology consisting of the root, shaft, and tip, and an inner morphology consisting of the cuticle, cortex, and medulla Wright, 2008. The outer structure consists of three parts: root, shaft, and tip. The root, the proximal end of the hair, connects the hair strand to the body. The root can be used to determine how and why the hair left the body. The shaft is the length of the hair between the root and the tip. It can be analyzed to determine: the origin of the hair from the body, the color of the hair, and the liner shape such as straight or curly. The tip, the distal end, can provide information such as breakage and cutting of the hair (Figure 1).

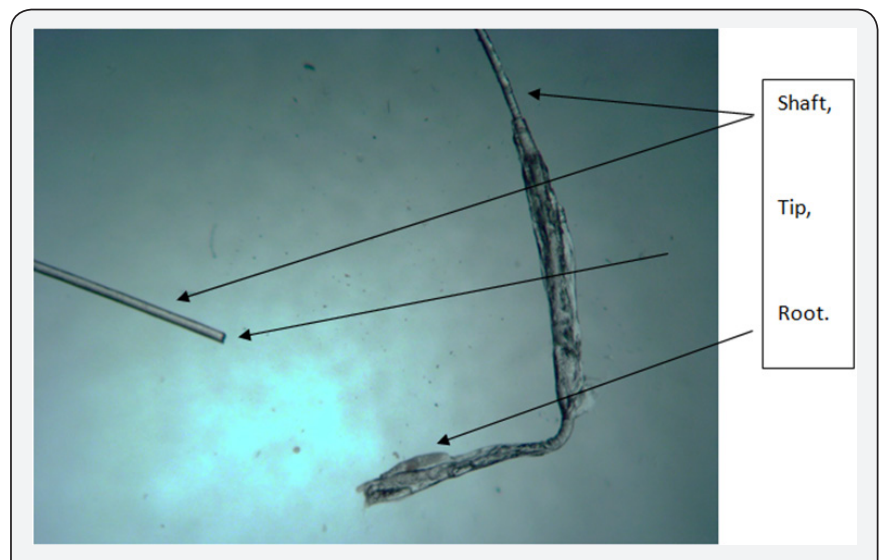

Figure 1: Freshly pulled human head hair.

An additional structural characteristic of hair consists of three parts: medulla, cortex, and cuticle. The cuticle is the outer layer of the shaft, and consists of scales. The scales can be used for species identification as they vary in shape and spatial structure [5]. The cortex is found throughout most of the internal hair and resembles a cylinder made up of fibers and protein material, and the medulla runs down the shaft taking up a fraction of the width of the hair strand [5]. Pigment granules distributed through the hair determine the color. These granules are typically located between the macrofilaments of the cortex. The color differs depending on how the granules are distributed, the number of granules and the size of the granules. Ortonne and Prota, note two primary types of hair color: Eumelanins are dark brown to black, and Phaeomelanins are reddish yellow [6]. Coloration is determined by which type is predominant [7].

Tridico [8] reported a case in Australia in which over 400 hundred hairs were examined, and the results used to associate a suspect with a homicide of two people. The examination involved examining the hairs with a stereomicroscope, light microscope, polarized light microscope, and Scanning Electron Microscope. It further involved getting many dog and cat hair samples and preparing statistical correlations between medullary indexes, morphological characteristics or roots, coloration bands, and scales. A unique facet of the investigation is that a suspect denied any contact with a dog of the victim, but had large concentrations of dog hair in the back seat of his motor vehicle, on his bed, and on his clothing.

\section{Reference Library}

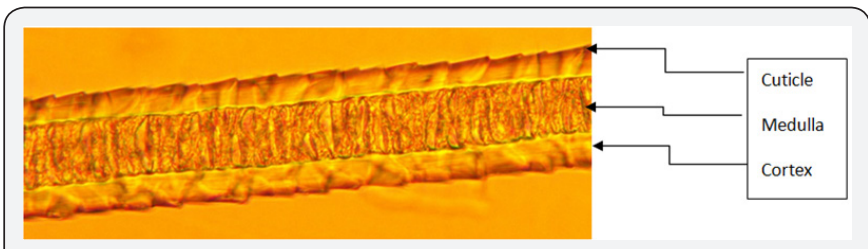

Figure 2: Canine, St. Bernard hair, shaft showing cuticle (scales), inner cortex, and medulla of the hair.

The following images were taken by the authors using a compound light microscope to show the differences between dog, cat and human hairs. As can be seen, the cortex, medulla, and cuticle can be very similar between cat and dog hairs. It is generally accepted among trace evidence forensic scientists that absent DNA analyses, identification of a hair based on only the shaft cannot be done with a high level of certainty to determine the origin as dog or cat. One can, however, often, distinguish between human and other animal hairs. As a rule, animal hairs usually have a medullary index greater than 0.5 while human medulla are generally less than this value [9]. This does not preclude that information from roots, scales, and coloration could not provide valuable differentiating information for further identification of animal versus human origins. The following images were used a reference when making decision on origin of samples gathered for this research (Figure 2).

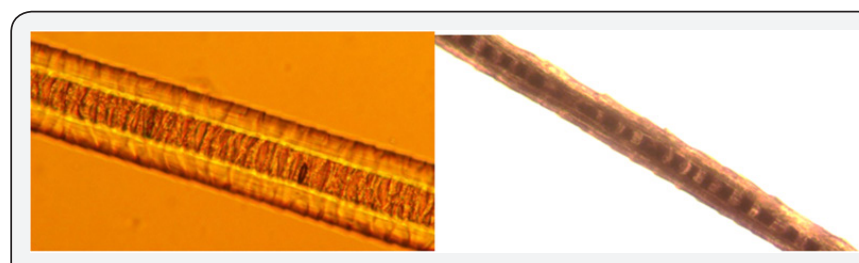

Figure 3: The image on the left is of hair from a Cavalier King Charles Spaniel. The image on the right is from a Canine, German Sheppard.

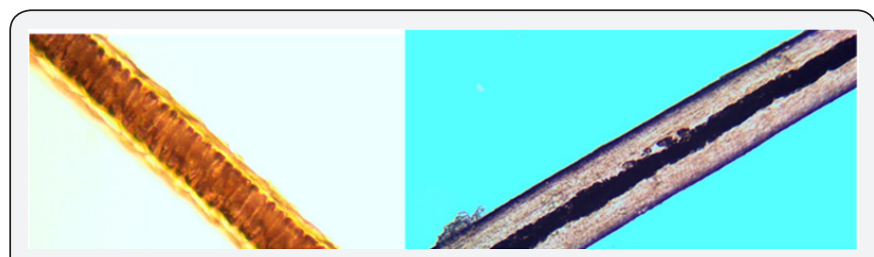

Figure 4 : The image to the left is of a Feline, Siamese, and the image to the right is of a human, male, chest hair.

Cat and Dog hairs are very difficult to distinguish one form the other. Medullas often look the same. In the same vein of thought it can be difficult to differentiate between cat hairs, dog hairs, and rodent hairs. We adopted the term cat/dog hairs as a general category that would be most consistent with animal hairs most likely found in motor vehicles in urban areas in the 
United States. They would be the hairs most likely to be ones in which an association would be proffered in a forensic case. Although some analysts suggest a distinction can be made between cat and dog hair, this usually involves a full length with the root and tips present in the hair sample and DNA analysis. Our research was to establish a general position based on the assumption that in a scene setting involving transfer of hair the most likely scenario would involve pieces of hair with only the hair shaft. The following images illustrate the commonality between cat and dog hairs. They also demonstrate the distinctive physical characteristics between human hairs and cart/dog hairs (Figures 3-5).

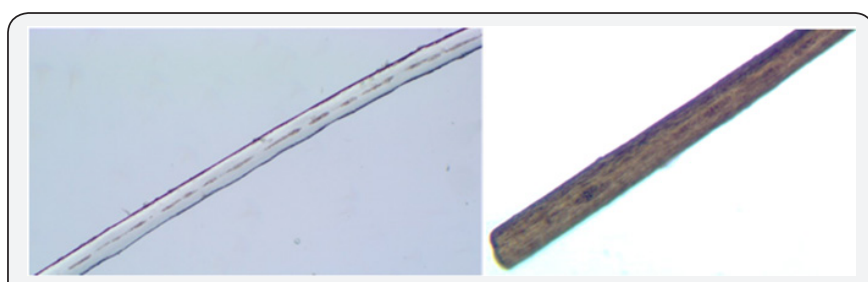

Figure 5 : the image on the left is of a human, male, head hair, and the image on the right is of a human female, head hair.

\section{Methods}

\section{Reference Library Preparation}

A veterinarian clinic was contacted and asked to provide cat and dog hair samples. Slides were prepared as reference samples. Slides were prepared with several different substances: Elmer's Glue, Balsam, Melt Mount, and Permount. Using the different mediums gave a little bit of a different perspective on each hair, as some were clearer than others. Once slides were prepared, they were examined with a compound light microscope and a phase contrast scope. Examinations were done at 100x and 400x magnification. Photomicrography images were taken of the hair on each slide. An Amscope, T690C, compound light microscope, and an Amscope, XSZ-N107E, phase contrast microscope was used to examine the hairs. An AmScope 3.7, version x86, 3.7.3980, and software package with an Am Scope MU500, 5.1 MP, and microscope eyepiece camera was used with a Toshiba, Satellite, C55 series laptop to capture digital images of hairs.

Permount seemed to provide the best detail when viewing with the microscopes. Additional useful information was not gotten using the phase contrast microscope as compared to the compound light microscope. The remainder of the research project was conducted using Permount and the compound light microscope. The slides were stored for reference.

\section{Study 1}

Twenty-four people granted permission to collect a hair sample from their vehicle. Samples were collected by using a piece of masking tape to pull the hair off the front two seats in each motor vehicle. The tape lift was immediately put into a clear, Ziploc bag, and sealed with the sample number and pet ownership information (Figure 6). Seven non-pet owners allowed taking samples. Seventeen pet owners allowed taking sample. This provided a total collection of twenty-four samples. The compound light microscope was used to examine each sample. This was done by viewing through the plastic bag to control for contamination from the environment of the microscope lab. This allowed one to clearly see the medulla and scales of hairs. The medulla characteristics were used to distinguish between animal hairs and non-animal fibers and structures, and to distinguish between human and non-human hair. In some cases, the scale characteristics were used to establish a human versus a non-human hair. The numbers of human and animal hairs were recorded for each sample.

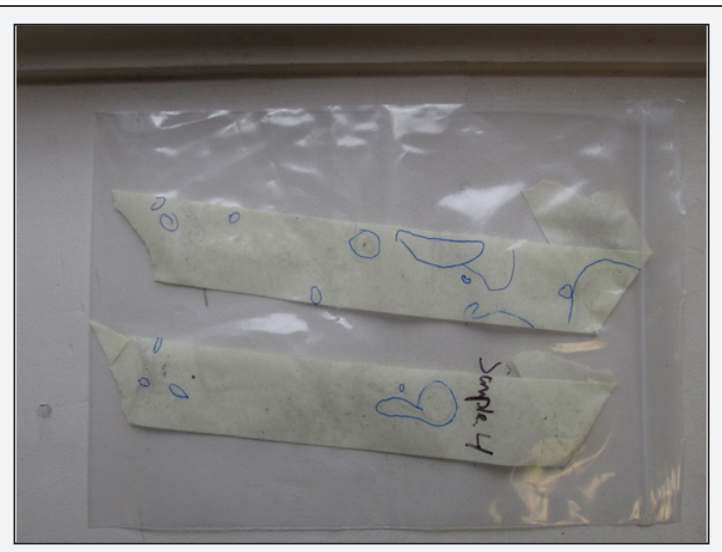

Figure 6 : An example of the tape lift method of collecting hairs, and marking hairs after viewing through a compound microscope.

\section{Study 2}

A motor vehicle salvage yard was contacted and asked for permission to take hair samples from front seats of motor vehicles. Twenty-one vehicles were selected that had intact bodies and windows, and had doors fully closed. Samples were collected using the same tape and Ziploc bag method used in Study one. The same microscope procedure was used as that with Study one.

\section{Results and Discussion}

\section{Study 1}

Table 1 shows the results from collecting volunteer samples from owners with pet information. In all twenty-four known owner vehicle samples either an animal or a human hair was collected. We used the term animal for brevity purposes in lieu of cat/dog hair. In two cases a human hair was not collected when an animal hair was collected. This was from pet owner vehicles. In twenty-two of twenty-four samples human hairs were collected. The success of getting a hair sample in each case confirmed that the tape lift method was a viable and successful technique for collecting samples. Seven people claimed to not have a pet or have contact with a pet of these seven; two did not have animal hairs. Of the seventeen who claimed to be pet owners, two did not have animal hairs. Of twenty-four samples, there were four in which there were not animal hairs. In the two 
cases in which the owner was a pet owner and no human hairs were found in the sample, animal hairs were found in the vehicle.

Table 1: The Human and Animal Hair found in known pet owner vehicles.

\begin{tabular}{|c|c|c|c|}
\hline $\begin{array}{l}\text { Sample } \\
\text { Number }\end{array}$ & Human Hair & Animal Hair & Pet Owner \\
\hline 1 & 1 & 0 & No \\
\hline 2 & 8 & 0 & Yes \\
\hline 3 & 3 & 2 & Yes \\
\hline 4 & 11 & 8 & Yes \\
\hline 5 & 9 & 25 & Yes \\
\hline 6 & 4 & 5 & Yes \\
\hline 7 & 16 & 7 & Yes \\
\hline 8 & 6 & 2 & No \\
\hline 9 & 21 & 16 & Yes \\
\hline 10 & 16 & 3 & No \\
\hline 11 & 4 & 5 & Yes \\
\hline 12 & 1 & 4 & Yes \\
\hline 13 & 5 & 1 & No \\
\hline 14 & 17 & 0 & No \\
\hline 15 & 10 & 18 & Yes \\
\hline 16 & 11 & 2 & No \\
\hline 17 & 20 & 40 & Yes \\
\hline 18 & 19 & 9 & No \\
\hline 19 & 0 & 1 & Yes \\
\hline 20 & 4 & 10 & Yes \\
\hline 21 & 0 & 2 & Yes \\
\hline 22 & 1 & 2 & Yes \\
\hline 23 & 1 & 0 & Yes \\
\hline 24 & 1 & 1 & Yes \\
\hline
\end{tabular}

Table 2: Frequencies of human and animal hair found in known owner vehicles.

\begin{tabular}{|c|c|c|c|}
\hline Status & Human Hair & Cat/Dog Hair & $\begin{array}{c}\text { Percent with } \\
\text { Cat/Dog Hair }\end{array}$ \\
\hline $\begin{array}{c}\text { Known Pet } \\
\text { Owner N=17 }\end{array}$ & 15 & 15 & $88 \%$ \\
\hline $\begin{array}{c}\text { Known Non- } \\
\text { Owner N=7 }\end{array}$ & 7 & 5 & $71 \%$ \\
\hline Total N = 24 & 22 & 20 & $83 \%$ \\
\hline
\end{tabular}

Table 2 shows simple frequency calculations. In $71 \%$ of the non-pet cases there were animal hairs. In $88 \%$ of the pet owner cases there were animal hairs. Overall, in $83 \%$ of the samples there were animal hairs. EXCEL was used to calculate a Chi-square value. The result was 0.25 for the animal hairs relationship to pet ownership. This is greater than the desired research value of 0.05 percent. We were not able to reject the null hypothesis that there was not a significant difference of animal hairs in vehicles based on pet ownership (Table 3).
Table 3: Chi-square test for significance of animal hairs in motor vehicles identified as pet owner or non-pet owner vehicles.

\begin{tabular}{|c|c|c|c|}
\hline Pet Status & $\begin{array}{c}\text { No Animal } \\
\text { Hair }\end{array}$ & Animal Hair & Total \\
\hline Pet Owner & $2(3)$ & $15(14)$ & 17 \\
\hline Non-pet Owner & $2(3)$ & $5(6)$ & 7 \\
\hline Total & 4 & 20 & 24 \\
\hline
\end{tabular}

\section{Study 2}

Table 4 shows the results of collecting samples from salvage yard vehicles. Animal hairs were found in nineteen of twentyone samples. Human hair samples were found in twenty-one of twenty-one samples. In no case was there an absence of animal and human hair in each sample. In the salvage vehicles, ninety percent of the vehicles had animal hairs. We were not able to go statistically beyond percentages since we did not have knowledge of the status of pet ownership related to each vehicle. It was interesting that in two cases there were not animal hairs. This gives an insight into a baseline that in high percentage of cases animal hairs, defined as cat or dog hairs, can be expected to be found in motor vehicles in the defined geographical region of this study.

Table 4: Human and animal hair found in salvage vehicles.

\begin{tabular}{|c|c|c|}
\hline Sample Number & Human Hair & Animal Hair \\
\hline 1 & 3 & 3 \\
\hline 2 & 4 & 15 \\
\hline 3 & 6 & 17 \\
\hline 4 & 8 & 6 \\
\hline 5 & 13 & 22 \\
\hline 6 & 17 & 7 \\
\hline 7 & 1 & 1 \\
\hline 8 & 9 & 11 \\
\hline 9 & 1 & 0 \\
\hline 10 & 1 & 0 \\
\hline 11 & 11 & 13 \\
\hline 12 & 1 & 1 \\
\hline 13 & 4 & 10 \\
\hline 14 & 6 & 3 \\
\hline 15 & 9 & 5 \\
\hline 16 & 7 & 5 \\
\hline 17 & 6 & 16 \\
\hline 18 & 1 & 2 \\
\hline 19 & 7 & 5 \\
\hline 20 & 1 & 2 \\
\hline 21 & 5 & 25 \\
\hline
\end{tabular}

\section{Conclusion}

The results of the research indicate that no significant difference in the distribution of animal hair between cars that owned by pet owners and cars owned by non-pet owners. 
This suggests, in a forensic context, that cat or dog hair or both, absent DNA analyses, would not be robust evidence for associating a person with a person, place, or thing without additional corroborating information. The animal hairs were environmentally ubiquitous. In the forensics field, there is a level of uncertainty without expectations of absolutes [10-12]. The research results suggest that animal hairs may be less useful than previously thought in terms of association based only on gross morphological characteristics. More distinct morphological characteristics and a larger number of hairs might add weight to the value of animal for association. Corroborating data such as DNA, fingerprints, fibers, and witness statements could add to the value of the hair. However, caution is in order inferring that presence of animal is a standalone piece of evidence to link a person place, or thing.

The age of sample vehicles, make and model of vehicle, year of vehicle, owner habit of cleanliness, and the nature of the pet in terms of long hair or short hair, prone to shed or not shed, were not taken into consideration. These variables could affect the results of distribution of hair. Only front seats were examined. Some pet owners might require pets to ride in back seats or to ride in containers. Low sample numbers were not in keeping with the ideal numbers for robust research and statistical analysis. Care was taken to make sure the tape lift process was effective in recovering hair. This was confirmed by the presence of human hair. In no case were hairs of some type not recovered in both studies Care was taken to collect sample from different venues. The results from the salvage yard and the owner vehicles were similar in most respects.

Our research presents a baseline for considering the value of cat and dog hairs in an associative role in a forensic examination. It suggests that animal hair can be ubiquitous in some environments. This is not proof that animal hair cannot be used for purposes of association between people, places, and things. It is information that posits caution in making hasty inferences without corroborating research and corroborating information. As an example, unique color characteristics of a hair and a potential source would present more weight to an association, and particularly so if several vehicles in the geographical region were searched for animal hair frequencies. Clearly animal hair information would offer greater weight in conjunction with corroborating information such as eyewitness or victim information, and other physical information such as fibers, fingerprints, pollen, and DNA analyses.

\section{Acknowledgement}

This research was supported by a University of NebraskaLincoln, UCARE grant. UCARE grants are for undergraduate research. More information on these grants can be found at http://ucare.unl.edu/. The research was further supported by the University of Nebraska-Lincoln College of Agricultural Sciences and Natural Resources (CASNR), and the Forensic Science Degree Program. Thanks to UCARE for financial support and CASNR for use of facilities and equipment.

\section{References}

1. Deedrick DW (2000) Hair Evidence. Forensic Science Communication $2(3)$.

2. Barksdale L (2016) Unpublished personal interview.

3. Grieve M, Houck MM (2004) The importance of trace evidence. In trace evidence analysis: more cases in mute witnesses. Houck MM (Eds.), Amsterdam: Elsevier Academic Press, Burlington, USA, p. 1-26.

4. Allocca S (2015) FBI Admits Flaws in Hair Analysis Spanning Two Decades. Forensic Magazine.

5. Goutam S (2008) An introduction to forensic hair examination. New Delhi: Selective \& Scientific Books.

6. Ortonne JP, Prota G (1993) Hair melanins and hair colour: ultrastructural and biochemical aspects. J Invest Dermatol 101(1): 82S-89S.

7. Jimbow K, Fitzpatrick TB, Wick MM (1991) Biochemistry and physiology of melanin pigmentation. In Physiology, biochemistry and molecular biology of the skin ( $2^{\text {nd }}$ edn). Goldsmith LA editor Oxford: Oxford University Press, USA, pp. 873-909.

8. Tridico G (2004) Hair of a dog: a case study. In Trace Evidence Analysis: More Cases in Mute Witnesses. In Houck MM (Eds.), Elsevier Academic Press, Burlington, USA, p. 27-52.

9. Hooke College of Applied Science (2001) Hair comparison. Westmont (IL): Hooke College of Applied Science.

10. Christensen AM, Crowder CM, Ousley S, Houck MM (2014) Error and it's meaning in forensic science. J Forensic Science 59(1): 123-126.

11. Deadman H (2004) The Importance of trace evidence. In Houck MM (Eds.). Trace evidence analysis: more cases in mute witnesses. Elsevier Academic Press, Burlington, USA, pp. 123-164.

12. Kirk PL (1953) Crime investigation physical evidence and the police laboratory. Interscience Publishers Inc New York, p. 1-4. 
This work is licensed under Creative

Commons Attribution 4.0 License

DOI: $10.19080 /$ JFSCI.2017.06.555680

\section{Your next submission with Juniper Publishers} will reach you the below assets

- Quality Editorial service

- Swift Peer Review

- Reprints availability

- E-prints Service

- Manuscript Podcast for convenient understanding

- Global attainment for your research

- Manuscript accessibility in different formats

( Pdf, E-pub, Full Text, Audio)

- Unceasing customer service

Track the below URL for one-step submission https://juniperpublishers.com/online-submission. 